\title{
Management and outcome of sonographically diagnosed uterine enhanced myometrial vascularity / arteriovenous malformations following early pregnancy events: a single center experience
}

\author{
Jennifer K.Y. Ko, Vincent Y.T. Cheung \\ Department of Obstetrics and Gynaecology, Queen Mary Hospital, The University of Hong Kong, Hong Kong
}

\section{To the Editor,}

Uterine enhanced myometrial vascularity (EMV), also known as arteriovenous malformations (AVM), is rare, usually acquired and developed following a pregnancy event.EMV is the term used recently to describe acquired AVM regardless of the presence or absence of products of gestation [1]. Some authors collectively name acquired vascular structures of the uterus identified by color Doppler as EVM/AVM [1].

The clinical significance of this finding and its management particularly in asymptomatic women is not well established. In the current series, we reviewed our experience on a group of women who had EMV/AVM diagnosed with color Doppler ultrasound after an early pregnancy event. This review had obtained ethical approval from the Institutional Review Board.

Between January 2010 and December 2013, EMV/ AVM was diagnosed in 22women with transvaginal Doppler ultrasound. Nine women $(41.0 \%)$ were asymptomatic at the time of diagnosis. Reasons for ultrasound examination included abnormal uterine bleeding in 12 women $(54.5 \%)$, reassessment after miscarriages in 9 women $(41.0 \%)$, and abdominal pain after surgical abortion in 1 woman (4.5\%). The typical finding on color Doppler ultrasound was atangle of tortuous vessels with multidirectional, high-velocity and turbulent flow (fig 1). The

Received 18.04.2016 Accepted 22.04.2016

Med Ultrason

2016, Vol. 18, No 3, 403-404, DOI: 10.11152/mu.2013.2066.183.kyk

Corresponding author: Vincent Y.T. Cheung

Department of Obstetrics and Gynaecology,

Queen Mary Hospital,

102 Pokfulam Road, Hong Kong

Phone: 852-22553914, Fax: 852-25173278

E-mail: vytc@hku.hk

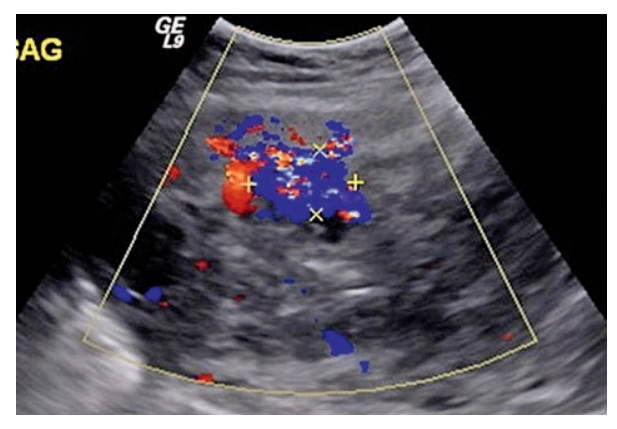

Fig 1. Typical color Doppler ultrasound appearance of EMV/AVM as shown in one of our cases.

median diameter of the hypervascular lesionin our series was $2.0 \mathrm{~cm}$ (range $1.0-3.2 \mathrm{~cm}$ ).

The demographics and clinical outcomes are summarized in Table I. Notably all asymptomatic women had spontaneous resolution of the EMV/AVM with no abnormal bleeding. However, 2 women (15.4\%) with abnormal bleeding remained symptomatic and ultimately required angiographic embolization. The median duration for sonographic resolution of the EMV/AVM was12weeks (range 2-52 weeks).

Nowadays, color Doppler ultrasound is considered the primary diagnostic tool for women with suspected uterine EMV/AVM [2,3]. In most of our cases, the diagnosis of EMV/AVM was not confirmed angiographically and often, the diagnosis can be confused with retained products of gestation $[4,5]$. Therefore, without angiography, whether these ultrasound findings represent vascular retained products of gestation will never be certain. Nevertheless, clinicians need to advise women who present with this ultrasound finding. Despite the small number in our series which precludes us from drawing firm conclusions, our study suggests that most women with 
Table I. Demographics and clinical outcomes between women with and without abnormal bleeding

\begin{tabular}{|c|c|c|c|}
\hline & \multicolumn{3}{|c|}{ Vaginal bleeding } \\
\hline & No $(n=9)$ & Yes $(n=13)$ & p value ${ }^{\wedge}$ \\
\hline Age (year) & $32.1+/-5.4$ & $31.1+/-6.7$ & 0.896 \\
\hline \multicolumn{4}{|l|}{ Prior pregnancy event } \\
\hline Spontaneous miscarriage & $2(22.2 \%)$ & $1(7.7 \%)$ & 0.119 \\
\hline Silent miscarriage, managed & $6(66.7 \%)$ & $5(38.5 \%)$ & 0.752 \\
\hline - Surgically & 0 & 3 & \\
\hline - Medically & 6 & 1 & \\
\hline - Medically + surgically & 0 & 1 & \\
\hline Pregnancy termination and methods & $1(11.1 \%)$ & $7(53.8 \%)$ & 0.074 \\
\hline - Surgically & 1 & 3 & \\
\hline - Medically & 0 & 4 & \\
\hline $\begin{array}{l}\text { Interval between pregnancy event and diagnosis of EMV/AVM in weeks } \\
\text { (median, range) }\end{array}$ & $1(1-5)$ & $6(0.4-12)$ & 0.004 \\
\hline Size of EMV/AVM in cm (median, range) & $2.0(1-2.7)$ & $2.0(1.1-3.2)$ & 0.808 \\
\hline \multicolumn{4}{|l|}{ Progress during follow up } \\
\hline No bleeding & $8(88.9 \%)$ & 0 & $<0.001$ \\
\hline Persistent bleeding & 0 & $2(15.4 \%)$ & 0.493 \\
\hline Bleeding resolved spontaneously & $1(11.1 \%)$ & $11(84.6 \%)$ & 0.002 \\
\hline Time to resolution of bleeding (for patients required no intervention, weeks) & not applicable & $0.3-3[n=10]$ & \\
\hline Time to resolution of EMV/AVM in weeks (median, range) & $8(4-52)[n=8]$ & $12(2-20)[n=10]$ & 0.633 \\
\hline \multicolumn{4}{|l|}{ Intervention } \\
\hline Uterine artery embolization & 0 & $2(15.4 \%)$ & 0.494 \\
\hline Blood Transfusion & $1(11.1 \%)$ & $1(7.7 \%)$ & 0.784 \\
\hline Defaulted follow up & $1(11.1 \%)^{*}$ & $1(7.7 \%)^{*}$ & 0.784 \\
\hline
\end{tabular}

Data are presented in $\mathrm{n}(\%)$ unless specified. ${ }^{\wedge}$ Calculation performed using Mann Whitney $\mathrm{U}$ test and Fisher's exact test where appropriate. Statistical significance when $\mathrm{p}<0.05$. *In both women the uterine lesions were shown to have reduced in size at their latest follow up visits 2 and 3 weeks after diagnosis.

sonographically diagnosed EMV/AVM following early pregnancy events can be reassured and be managed expectantly with ultimate resolution of the lesions. Only a small number of women with persistent and heavy bleeding will require angiographic intervention.

\section{References}

1. Timor-Tritsch IE, Haynes MC, Monteagudo A, Khatib $\mathrm{N}$, Kovács S. Ultrasound diagnosis and management of acquired uterine enhanced myometrial vascularity/arteriovenous malformations. Am J Obstet Gynecol 2016; 214 : 731.e1-731.e10.
2. O'Brien P, Neyastani A, Buckley AR, Chang SD, Legiehn GM. Uterine arteriovenous malformations: from diagnosis to treatment. J Ultrasound Med 2006; 25: 1387-1392.

3. Pan HA, Kuo PL. Transvaginal color Doppler ultrasonography for detecting acquired arteriovenous malformation of the uterus. Taiwan J Obstet Gynecol 2002; 14: 25-29.

4. Aslan H, Acar DK, Ekiz A, et al.Sonographic features and management options of uterine arteriovenous malformation. Six cases report. Med Ultrason. 2015;17:561-3.

5. Vilos AG, Vilos GA, Hollett-Caines J, Rajakumar C, Garvin G, Kozak R. Uterine artery embolization for uterine arteriovenous malformation in five women desiring fertility: pregnancy outcomes. Hum Reprod 2015; 30: 1599-1605. 


\title{
Pelvic cystic mass and ipsilateral renal agenesis detected by ultrasound in a young girl: early onset of Herlyn-Werner-Wunderlich Syndrome.
}

\author{
María Fernández-Ibieta ${ }^{1}$, Esperanza Hernández-Anselmi², María Soledad Fernández- \\ Córdoba ${ }^{2}$
}

${ }^{1}$ Pediatric Surgery Department, Hospital Clínico Univeritario V Arrixaca, Murcia, ${ }^{2}$ Pediatric Surgery Department, Hospital Universitario General de Albacete, Albacete, Spain

\section{To the Editor,}

Uterus didelphys with Obstructed HemiVagina and Ipsilateral Renal Agenesia (OHVIRA) syndrome is usually named Herlyn-Werner-Wunderlich syndrome (HWWs) [1]. A disorder in the lateral fusion of the Müllerian ducts, results in an uterus didelphys with a longitudinal vaginal septum, with a blind hemivagina and a renal anomaly such as dysplastic kidney or renal agenesis $[1,2]$. The accumulation of uterine secretions in the obstructed side in prepubertal girls or menses in the adolescent, can lead to the formation of cystic masses in the hemiuterus or hemivagina, such as hematometra, pyohematocolpos, or even pelvi-peritonitis if complicated with extended infection. The most prevalent clinical presentations are dysmenorrhea and menstrual abnormal bleeding, or cyclic pain in adolescents [1-3].

A 6-year-old female with complaint of intermittent pain in the lower abdomen of two months duration was evaluated in the Pediatric day hospital. The patient showed a distended abdomen and normal external genitalia. Ultrasound (B mode with a conventional convex 8 $\mathrm{MHz}$ sound) showed the absence of a right kidney, and a 11 x $9 \mathrm{~cm}$ cystic pelvic lesion with internal echogenicities (fig 1a). MRI revealed two uterine corpii and double vagina, one of them distended with fluids: a pyometro-

Received 28.04.2016 Accepted 05.05.2016

Med Ultrason

2016, Vol. 18, No 3, 405-406, DOI: 10.11152/mu.2013.2066.183.ibi

Corresponding author: Dr Maria Fernández-Ibieta

Pediatric Surgery Department. Hospital C.

Universitario V Arrixaca.

Crta El Palmar, s/n. 30012, Murcia, Spain.

Phone: +34-968-369693

E-mail: mfndezibieta@hotmail.com

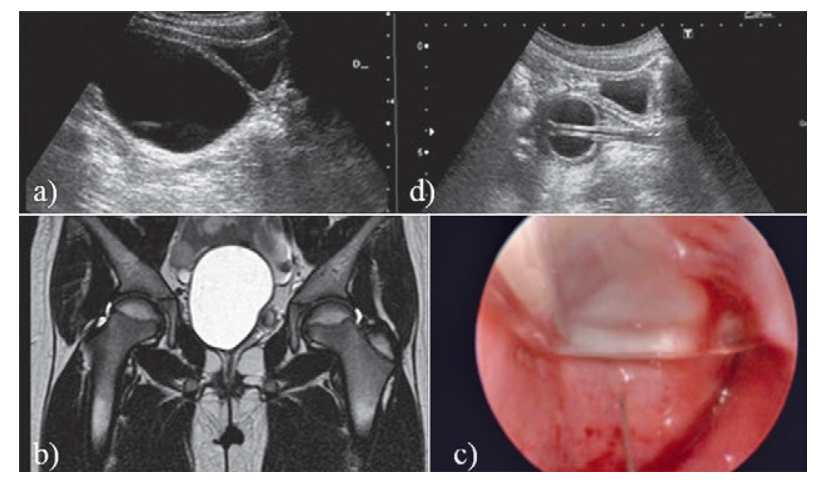

Fig 1. a) Ultrasound before septotomy: paravesical large cyst corresponding to pyocolpos; b) MRI (T1) revealed two uterine corpii and double vagina, one of them distended with fluids: a pyometrocolpos and a thick hypointense right hemivaginal septum caudal to pyometrocolpos; c) appearance of the blinded hemivagina (septum) on vaginoscopy; d) a Foley catheter inserted in the emptied hemivagina after septotomy

colpos, that appeared hyperintense on T1WI (fig 1b). Additionally, right renal agenesis was noted. Ovaries were normal. A diagnosis of Herlyn-Werner-Wunderlich or OHVIRA syndrome was pointed out and the patient underwent a vaginoscopic vaginal septectomy (fig 1c). A 14 Fr Foley catheter was left in the right hemivagina for 9 days (fig 1d). The girl was discharged home on the next day. After 10 months follow up, the girl remains symptom free, and her ultrasounds are normal.

Müllerian duct anomalies, such the HWW /OHVIRA syndrome, have an incidence of $1-5 \%$ in the general population, constituting $0.16-10 \%$ in women with recurrent pregnancy loss [1,4-7]. Patients with HWW /OHVIRA are usually asymptomatic until menarche when they present a hydrometrocolpos on the obstructed site, producing a mass effect and pain. Retrograde menstruation may 
cause distension of the fallopian tubes and hematosalpinx and endometriosis (17\%), pelvic adhesions and increased risk of infertility [6,7]. After surgery (septal resection), prognosis is good, with the mayor concern being preservation of fertility. Women with uterus didelphys have a high likelihood of becoming pregnant, with approximately $80-85 \%$ of patients able to conceive, but with elevated rates of premature delivery (22\%) and abortion (74\%); caesarean section is necessary in over $80 \%$ of patients $[6,7]$.

Vaginal septotomy is accomplished most commonly through hysteroscopic/ vaginoscopic approach. Stenosis of the vaginal septum after surgery can be resected again safely. Either total or unilateral hysterectomy $[6,7]$ may be required in cases in which septal resection is not possible and may be also considered in patients with recurrent stenosis and severe endometrial/uterine infection; or in patients who do not wish further pregnancies [9]. If immediate surgery is not an option, oral contraceptives or gonadotropin-releasing hormone analogues are advised $[6,7]$.

\section{References}

1. Mehra S, Chamaria K, Garga UC, Kataria A, Ahuja A. Imaging diagnosis of Herlyn-Werner-Wunderlich SyndromeAn Extremely Rare Urogenital Anomaly. J Clin Diagn Res 2015; 9: TD06-TD08.

2. Yavuz A, Bora A, Kurdoglu M, et al. Herlyn-Werner-Wunderlich Syndrome: merits of sonografic and magnetic resonance imaging for accurate diagnosis and patient management in 13 cases. J Pediat Adolesc Gynecol 2015; 28: 47-52.

3. Zhu L, Chen N, Tong JL, Wang W, Zhang W, Lang JH. New classification of Herlyn-Werner-Wunderlich syndrome. Chin Med J 2015; 128: 222-225.

4. Orazi C, Lucchetti MC, Schingo PM, Marchetti P, Ferro F. Herlyn-Weiner-Wunderlich syndrome: uterus didelphys, blind hemivagina and ipsilateral renal agenesis. Sonographic and MR findings in 11 cases. Pediatr Radiol 2007; 37: 657-665.

5. Gholoum S, Puligandia PS, Hui T, Su W, Quiros E, Laberge JM. Management and outcome of patients with combined vaginal septum, bifid uterus and ipsilateral renal agenesis (Herlyn-Werner-Wunderlich syndrome). J Pediatr Surg 2006; 41: 987-992.

\title{
Imaging findings of obstructive sialadenitis due to an intraglandular foreign body
}

\author{
Ali Bekir Kurt ${ }^{1}$, Hasan Öztürk ${ }^{1}$, Mukadder Korkmaz ${ }^{2}$, Alpay Haktanır ${ }^{1}$
}

${ }^{1}$ Department of Radiology, Ordu University Medical School, Ordu, Turkey, ${ }^{2}$ Department of Otorhinolaryngology Head and Neck Surgery, Ordu University Medical School, Ordu, Turkey.

\section{To the Editor,}

Obstructive salivary gland diseases are among the most common salivary gland disorders causing salivary dysfunction and consequential sialoadenectomy. Most frequent causes are sialolithiasis and strictures in main ducts. Apart from endogenous pathologies, there is limited number of reports on exogenous obstructive factors

Received 27.04.2016 Accepted 04.05.2016

Med Ultrason

2016, Vol. 18, No 3, 406-407, DOI: 10.11152/mu.2013.2066.183.bek

Corresponding author: Alpay Haktanır

Ordu Universitesi, Tip Fakultesi, Radyoloji AD, 52200, Ordu, Turkey

E-mail: dralpay@gmail.com in the literature[1-6]. Among those previous papers, we could not find any comprehensive description of radiologic findings for foreign body induced sialadenitis. Here, we present the sonography and computed tomography (CT) findings of a patient with a very rare foreign body obstruction of the intraglandular duct of submandibular gland.

A 31-year-old male patient was referred for swelling, pain, and temperature rise in the left submandibular region for one year. In anamnesis, he described that a grass blade had splashed into his mouth during mowing the grass with a scythe. The patient had taken different nonspecific treatments in various appointments for the left submandibular swelling. His condition had wors- 


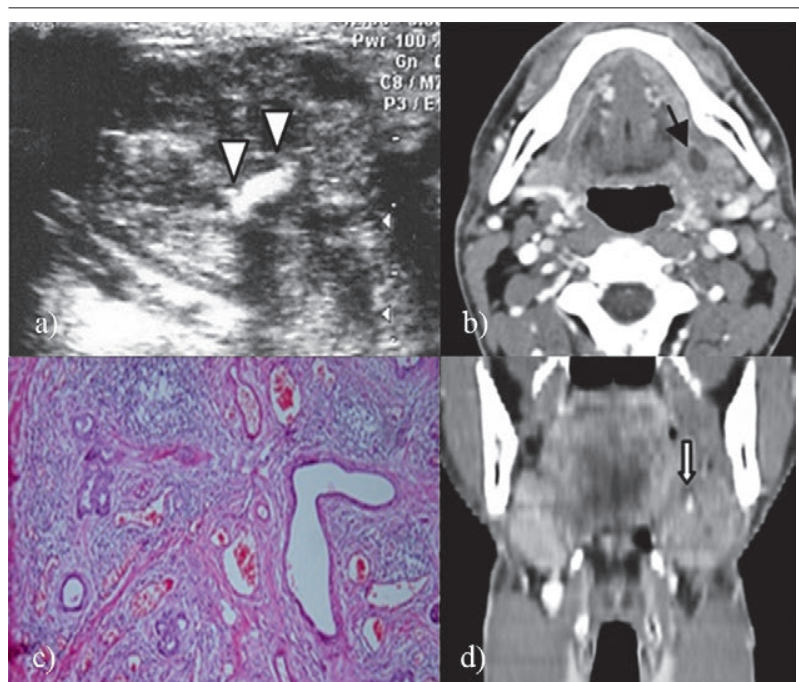

Fig 1. a) Sonographic image of the left submandibular gland: echo loss in the glandand intracanalicular echoic foreign body (arrowheads); b) and d) dilatation of left submandibular canal (black arrow) and hyperdense image in the canal (white arrow) in transverse (b) and reformatted coronal (d) contrast enhanced CT slices; c) ductal dilatations and findings of chronic sialadentis are seen in the pathologic specimen, H\&Ex20.

ened and his complaints had gradually increased. Physical examination did not reveal any abnormality except tenderness and swelling of the left submandibular region. Laboratory values were normal. Sonography showed enlargement, heterogeneity, increased vascularity, and ductal dilatation in the left submandibular gland. There was linear echogenicity with smooth borders in the intraglandular part of Wharton duct. Contrast-enhanced CT revealed a hypo-attenuated, 10x7 $\mathrm{mm}$ lesion in the gland. Left sialadenectomy was performed for obstructive submandibular sialadenitis. In the pathological examination, a $4 \times 3 \times 1.5 \mathrm{~cm}$ brownish capsulated tissue had a smooth outer surface. A yellow object with a $0.4 \mathrm{~cm}$ diameter was seen in a cystic lesion that was assumed to be a salivary duct. Sialadenitis was diagnosed histologically (fig 1).

Obstructive sialadenitis via retrograde migration is extremely uncommon because of the continuous excretory flow in the duct, small diameter and mobility of the ductal orifice, and presence of a sphincter-like mechanism in the distal $3 \mathrm{~cm}$ of the duct [2].In the last four decades, 22 cases with foreign bodies in the submandibular gland have been reported. Only one case of those reports described an intraglandular one; the rest were in the main duct in 14 cases, gland parenchyma in one case, and there was no knowledge about the localization in six cases[4]. Our case had an intraglandular foreign body, which, to the best of our knowledge, has been reported only once previously. Patients may present with acute infection findings or have an insidious course. In our patient, acute infection findings had caused frequent hospital admissions. For this reason, foreign body induced obstructive sialadenitis should be kept in mind in patients with sialadenitis with unexplained origin.

Foreign body induced submandibular gland obstruction and sialadenitis is rare and should be discriminated from endogenous pathologies by clinical evaluation and appropriate radiological work-up. Good knowledge of radiologic appearance of this disease can facilitate the exact diagnosis and treatment.

\section{References}

1. Marchal F, Kurt AM, Dulguerov P, Lehmann W. Retrograde theory in sialolithiasis formation. Arch Otolaryngol Head Neck Surg 2001; 127: 66-68.

2. Pratt LW. Foreign body of Wharton's duct with calculus formation. Ann Otol Rhinol Laryngol 1968; 77: 88-93.

3. Su YX, Lao XM, Zheng GS, Liang LZ, Huang XH, Liao GQ. Sialoendoscopic management of submandibular gland obstruction caused by intraglandular foreign body. Oral Surg Oral Med Oral Pathol Oral Radiol 2012; 114: e17-e21.

4. Ardekian L, Klain H, Peled M. Obstructive sialadenitis of submandibular gland due to foreign body successfully treated by sialoendoscopic intervention. J Oral Maxillofac Surg 2009; 67: 1337-1339.

5. McLoughlin LM, Dornan O. "Bird fancier's mouth," an unusual case of obstructive sialadenitis. Ulster Med J 2002; 71: 142-143.

6. Som PM, Shugar JM, Train JS, Biller HF. Manifestations of parotid gland enlargement: radiographic, pathologic, and clinical correlations. Part II: The diseases of Mikulicz syndrome. Radiology 1981; 141: 421-426. 


\title{
A web-based modern ultrasound diagnostic scanner simulation (SimulUS) for undergraduate medical e-learning education
}

\author{
Christian Kollmann', Marko Flor², Robert Bader ${ }^{2}$ \\ ${ }^{1}$ Center for Medical Physics \& Biomedical Engineering, Medical University of Vienna, ${ }^{2}$ Höhere-Technische Lehran- \\ stalt (HTL) Mistelbach, Biomedical Div. Mistelbach, Austria
}

\section{To the Editor,}

The methodology in teaching medicine has undergone major changes in the last 2 decades by connecting theoretical lessons with practical demonstrations or at least simulations from the earliest semester onwards. Ultrasound imaging became very popular in undergraduate medical education because of its intuitive, easy-to-understand methodology and mobile utility [1]. Classical teaching is combined with blended-learning, e-learning and team-based learning aspects. In the last years ultrasound skills-labs have been established at various universities to cover the requirements of early hands-on training and professional competence [2-4]. Embedding these courses within the curriculum can be a very large challenge for a university regarding financial, personnel or equipment resources. Ultrasound diagnostic scanners must be available in sufficient numbers and well-equipped to demonstrate and practice the common applications to undergraduates as used in clinical routine procedure. Nowadays ultrasound simulators could fill some of the gaps but their price level is sometimes equal to that of a mid-class diagnostic scanner and do not offer the haptic feeling in most cases nor are ideal to learn the basic equipment functions or knobology [5-7].

Received 31.05.2016 Accepted 06.06.2016

Med Ultrason

2016, Vol. 18, No 3, 408-409, DOI: 10.11152/mu.2013.2066.183.kol

Corresponding author: Christian Kollmann, Assist. Prof Dr. (PhD)

Center for Medical Physics \& Biomedical

Engineering, c/o AKH Wien 4L,

Währinger Gürtel 18-20,A-1090 Vienna;

Phone, +43-1-40400-73730,

Fax: +43-1-40400-39880,

E-mail: christian.kollmann@meduniwien.ac.at

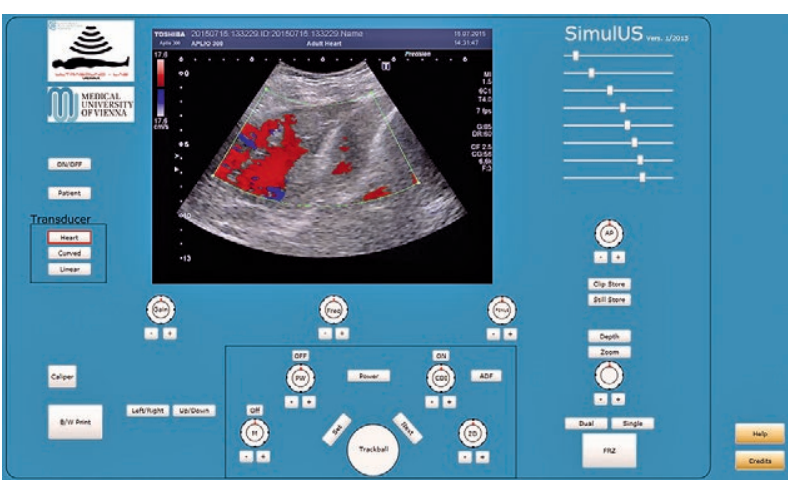

Fig 1. Snapshot of the Colour Doppler cineloop representation using the heart application selection of SimulUS

For this purposes we developed a special HTMLbased application to become familiar with the basic functions and settings of a modern ultrasound diagnostic scanner platform (SimulUS, fig1). This application complies with the special needs of undergraduates and other essential benefits (Table I).

In total more than 25 different basic functions, modes and setups can be selected interactively, such as selection of transducers, TGC, gain, focal setting, penetration depth, zoom, freeze or measure. Additionally to the basic ultrasound B- (brightness) Mode manipulations, Doppler-Mode, and M-Mode features are integrated, too. Through these, the tool can simulate "live" the effects of common application changes of a modern scanner for a clinical simulated situation by using Spectral-, Colour-, Power-Doppler or Advance Doppler Flow mode.

The tool SimulUS has been integrated into the official medical e-education environment of our university to allow all regular students $(\approx 550 / \mathrm{yr})$ easy web-based online or off-line access $[8,9]$ and to prepare mandatory practical weeks or skills-lab sessions on an individual base. We 
Table I. Practical points using the SimulUS application

Web-based ultrasound scanner solution (personalized back-end device)

Allows to reduce temporal and equipment resources in hands-on/skills-labs

Fits the personal needs of students concerning learning mobility and disposability

(24/7 available)

Self-guided (visual feedback)

Fun-related (interactive)

No costs (free download/access)

Deepens theoretical knowledge by interactive feedback

Encourages students to optimize image settings whenever they scan

pursued an easy-to-program approach involving 6 interested high-school students during a summer internship to demonstrate the feasability to develop an interactive ultrasound console for medical e-learning within 4 weeks and a total working time of ca. 420 hours for the goal of combining common high school/university teaching aspects.

Acknowledgement: This project has been funded in part by the Austrian Research Promotion Agency (FFG) under the program scheme "Talente" (project \# $851538 / 2015$ ). Many thanks for the great help of highschool students Melanie Liu, Patrick Röschl, Fabian Vaz, and Hanna Wursag for cineloop acquisition, cutting, or documentation.

\section{References}

1. Mircea PA, Badea R, Fodor D, Buzoianu AD. Using ultrasonography as a teaching support tool in undergraduate medical education - time to reach a decision. Med Ultrason 2012; 14: 211-216.

2. Butter J, Grant TH, Egan M, et al. Does ultrasound training boost year 1 medical student competence and confidence when learning abdominal examination? Med Educ 2007; 41: 843-848.

3. Gogalniceanu P, Sheena Y, Kashef E, Purkayastha S, Darzi A, Paraskeva P. Is basic emergency ultrasound training feasible as part of standard undergraduate medical education? J Surg Educ 2010; 67: 152-156.

4. Griksaitis MJ, Scott MP, Finn GM. Twelve tips for teaching with ultrasound in the undergraduate curriculum. Med Teach 2014; 36: 19-24.

5. Sidhu HS, Olubaniyi BO, Bhatnagar G, Shuen V, Dubbins P. Role of simulation-based education in ultrasound practice training. J Ultrasound Med 2012; 31: 785-791.

6. Parks AR, Atkinson P, Verheul G, LeBlanc-Duchin D. Can medical learners achieve point-of-care ultrasound competency using a high-fidelity ultrasound simulator?: a pilot study. Crit Ultrasound J 2013; 5: 9.

7. Bentley S, Mudan, Strother C, Wong N. Are Live Ultrasound Models Replaceable? Traditional versus Simulated Education Module for FAST Exam. West J Emerg Med 2015; 16: 818-822.

8. Simulus as e-resource database. Medical Univ. Vienna. Retrieved June 1, 2016. Available from: https://m3e.meduniwien.ac.at/lp/SimulUS

9. Simulus software. Center for Medical Physics \& Biomed. Eng., Medical Univ. Vienna. Retrieved June 1, 2016. Available from: http:/www.zmpbmt.meduniwien.ac.at/ forschung/ultrasound-lab/projects/simulus/

\section{Erratum}

Correction to Lenghel LM, et al. The ultrasonographic diagnosis of cystic cervical lesions: a pictorial essay. Med Ultrason 2016; 18(2): 240-246

The authors have been made aware of the error that appeared in the acknowledgments.

The correct acknowledgments: This paper was published under the frame of European Social Fund, Human Resources Development Operational Programme 2007-2013, project no. POSDRU/159/1.5/S/138776 